\title{
Uterine Corpus Intravenous Leiomyomatosis
}

National Cancer Institute

\section{Source}

National Cancer Institute. Uterine Corpus Intravenous Leiomyomatosis. NCI Thesaurus. Code $C 5356$.

A rare benign neoplasm characterized by the presence of smooth muscle cells growing within the veins of the uterine corpus. The intravascular neoplasm growth occurs outside the confines of an adjacent leiomyoma. 